\title{
Survey
}

\section{A Survey on Teaching Ultrasound-Guided Chronic Pain Procedures in Pain Medicine Fellowship Programs}

Bassem O. Asaad, MD, Ruth A Reinsel, PhD, Eric DeVeaux, MD, Hadi Moten, MD, and Brian Durkin, DO From: Stony Brook Medicine,
Stony Brook, NY

Address Correspondence: Bassem O. Asaad, MD Stony Brook Medicine Dept. of Anesthesiology Health Science Center

L4-06o 101 Nicolls Road Stony Brook, NY E-mail:

Bassem.Asaad@ stonybrookmedicine.edu

Disclaimer: There was no external funding in the preparation of this manuscript.

Conflict of interest: Each author certifies that he or she, or a member of his or her immediate family, has no commercial association

(i.e., consultancies,

stock ownership, equity interest, patent/licensing arrangements, etc.) that

might pose a conflict of interest in connection with the submitted manuscript.

Manuscript received: o2-14-2014 Accepted for publication: 06-20-2014

Free full manuscript: www.painphysicianjournal.

com
Background: Over the last decade ultrasound guidance (USG) has been utilized very successfully in acute pain procedures to confirm nerves' anatomic location and obtain live images. Not only the utilization, but the teaching, of USG has become an essential part of anesthesiology residency training. Prior to the introduction of USG, chronic pain procedures were always done either under fluoroscopy or blindly. USG offers advantages over fluoroscopy for completion of chronic pain procedures. USG decreases radiation exposure and the expenses associated with operating a fluoroscopy machine and allows live visualization of soft tissues and blood flow, a feature that fluoroscopy does not directly offer. Even today, the utilization and teaching of the technique for chronic pain procedures has not been as widely accepted as in acute pain management.

Objectives: To understand the current practices and the factors affecting the teaching of ultrasound guided chronic pain procedures in chronic pain fellowship programs throughout the United States.

Study Design: Survey conducted by internet and mail. The survey was distributed to program directors of ACGME-accredited pain medicine fellowships. When the survey was distributed there were 92 accredited pain medicine fellowships.

Methods: REDCap survey software was used for designing the questionnaire and sending email invitations. Also, paper questionnaires were sent to those who did not respond electronically. Additional copies of the survey were mailed or faxed upon request. We received 43 responses (a response rate of $46.7 \%$ ). Statistical analyses included frequencies, crosstabs, and nonparametric Spearman rank-order correlations.

Results: The majority of stellate ganglion blocks, occipital nerve blocks, and peripheral nerve blocks are currently being done under ultrasound guidance. Although interest among trainees is very high, only $48.8 \%$ of the fellowship programs require fellows to learn the technique before graduation and $32.6 \%$ of the program directors agree that teaching of USG should be an ACGME requirement for pain medicine fellowship training. Faculty training is considered to be the most important factor for teaching the technique by $62.8 \%$ of directors. In the opinion of the majority of program directors, the greatest factor that stands against teaching the technique is the fact that it is time consuming. Nearly half $(44.2 \%)$ of program directors believe that the technique will never replace fluoroscopy; but one quarter $(25.6 \%)$ think that the new 3D ultrasound technology, when available, will replace fluoroscopy.

Limitations: A moderate response rate (46.7\%) may limit the generalizability of the findings. However, our survey respondents seem to represent the study population quite well, although there was a bias towards the university-based programs. Training programs located at community-based hospitals and U.S. government installations were not as well represented.

Conclusion: The teaching of ultrasound guided chronic pain procedures varies significantly between individual programs. Though many program directors do require that fellows demonstrate competency in the technique before graduation, as of today there is no ACGME guideline regarding this. The advancement in ultrasound technology and the increase in number of trained faculty may significantly impact the use of USG in training fellows to perform chronic pain procedures.

Key words: Ultrasound guidance, fluoroscopy, chronic pain procedures, regional nerve blocks, musculoskeletal procedures, implantable devices, pain medicine, fellowship training, anesthesia residency training

Pain Physician 2014; 17:E681-E689 


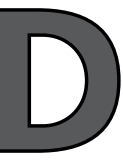

uring the last decade, the use of ultrasound guidance (USG) techniques in regional anesthesiology has increased significantly to the extent that in most institutions, it has not only replaced the current neurostimulation technique but has become the standard for completing regional anesthesiology procedures $(1,2)$. A recent survey on teaching USG in anesthesia residency training programs found that $75 \%$ of the training programs utilized USG for nearly all single injection and continuous peripheral nerve blocks (3). In chronic pain management, pain specialists have started to use the technique for chronic pain procedures in an attempt to reduce the utilization of fluoroscopy. Even today, in spite of this technique being used by many providers for many chronic pain procedures (4-6), we still lack information about the current extent of training in the use of USG techniques in chronic pain fellowships.

We developed a survey study to evaluate the current teaching of ultrasound guided chronic pain procedures in the United States. All chronic pain fellowship program directors (92 programs at the time the survey was distributed) were invited to participate. Our objective was to reach a conclusion about the current practice and teaching of the technique, find all the factors that influence its usage, and be able to provide recommendations regarding teaching of the technique in ACGME-accredited fellowship programs.

\section{Methods}

Following accepted research practices for surveys (7), we conducted a combined mailing and internetbased survey of current practices and teaching of ultrasound guided chronic pain procedures in ACGMEaccredited programs in the United States. This included collecting information about the utilization and teaching of the technique for the most commonly performed chronic pain procedures. This study was approved by the IRB at Stony Brook University.

\section{Sampling}

The targeted respondents were the directors of ACGME-accredited pain fellowships in the United States. Between May 2012 and January 2013, we contacted all the ACGME-accredited pain fellowship programs in the United States as of $2012(n=92)$. Contact information for program directors was extracted from the American Medical Association (AMA) database FREIDA. In cases where the program director's personal contact information was not given on FREIDA, every effort was made to find this information on the individual website of each program.

\section{Procedures}

The survey itself was implemented using REDCap (Research Electronic Data Capture) Consortium software (8) hosted on a website maintained by the Clinical Research Core (CRC) at Stony Brook University Hospital. REDCap (www.project-redcap.org) is a secure, webbased application designed to support data capture for research studies, providing: 1) an intuitive interface for validated data entry; 2 ) audit trails for tracking data manipulation and export procedures; 3) automated export procedures for seamless data downloads to common statistical packages; and 4) procedures for importing data from external sources.

Email addresses for program directors or their designated program administrators were entered into the REDcap website. Automated emails were sent to each program using standardized text. Responses were collected anonymously by the REDcap program; however, it was possible to separate responders (in general) from non-responders without breaking the anonymity of the individual survey responses. Two sets of personalized follow-up emails were sent to non-responders. Personalized follow-up phone calls were made on the same day of sending the second follow-up email. Written questionnaires were mailed to program directors who failed to respond to the three email invitations. Follow-up phone calls were made about a week after the survey mailing to personally request program directors to complete and return the questionnaire. Duplicate questionnaires were provided by mail or fax when personally requested.

\section{Incentive}

Participants were offered the opportunity to receive a Starbucks gift card (\$10) after completing the survey as a token of appreciation. Upon completion of the survey on the REDCap website, an email was sent to the respondents inviting them to provide their mailing address and a Starbucks gift card would be sent to them. Due to the separation of responses and mailing address information, anonymity was preserved.

\section{Statistical Analysis}

Responses to the survey were cumulated on the REDCap website and downloaded for analysis using Excel and IBM SPSS Statistics v. 21.0. Statistical analyses included frequencies, crosstabs, and nonparametric Spearman rank-order correlations. 


\section{Results}

\section{Sample of Survey Respondents}

Response Rate. Forty-three completed surveys were received from the 92 programs contacted, yielding a $46.7 \%$ response rate. Forty-two (97.7\%) of the responses were from program directors; one response was received from another faculty member in the program. Twenty-six $(61.9 \%)$ of the responses were made through the REDCap internet survey link and $17(39.5 \%)$ responses came from the mailing of the printed survey. Among the total population of fellowship programs surveyed, $78.7 \%$ were university-based, $16.9 \%$ were community hospitals with an academic affiliation, and $4.5 \%$ were U.S. government facilities. Our survey respondents followed this general pattern, however university-based programs were more heavily represented than non-academic training centers. Only 9.3\% of our survey respondents were drawn from a community-hospital setting, and only one respondent represented the private practice model. Pain management programs in U.S. government facilities were also under-represented, with what appears to be one response. Regarding program size, in the study population, about $39 \%$ of programs had 3 or fewer residency spots per year. Among our survey respondents, $46.5 \%$ of programs reported 3 or fewer residency training spots. Therefore it would seem that the smaller programs are slightly over-represented in our sample, as well as those based in academic centers.

\section{Program Characteristics}

Table 1 summarizes the results of the survey and the characteristics of programs which returned survey responses. The great majority $(88.4 \%)$ of the responding programs are university-based $(n=34,79.1 \%$ ) or university-affiliated ( $n=4,9.3 \%)$. Four programs $(9.3 \%)$ were based at community hospitals, one followed the private practice model, and one program described itself as "other" (probably a military program but unfortunately we cannot confirm this because the responses were anonymous). For the purpose of analysis, the 4 university-affiliated programs, the 4 communitybased hospitals, and the single "other" program were grouped together in order to provide a larger group of non-university programs.

\section{Program Size and Duration}

The number of ACGME-accredited fellowship spots per program ranged from 1 to 9 (approximate median $=3$ ). All responding fellowship programs were 12 months in duration. Only 2 programs (4.7\%) specified that they allowed an optional extra year for research.

\section{Prior Residency Training of Pain Fellows}

The number of fellows with anesthesia-residency training was expressed as a percentage of the total number of fellowship spots in the program. The median value fell approximately at $75 \%$, indicating that 3 out of every 4 pain fellows nationally have anesthesia training backgrounds. This is consistent with the multidisciplinary emphasis in the ACGME-accreditation program requirements for pain medicine fellowship training (9). The data are severely negatively skewed, with a large number of programs $(n=17,39.5 \%)$ where all of the pain fellows had prior anesthesia training. Among the fellows, interest in learning ultrasound is high; $69.8 \%$ of programs state that more than $90 \%$ of their fellows

Table 1. Characteristics of pain medicine fellowship programs responding to survey ( $N=43$ ) and breakdown of responses to key questions by program characteristics.

\begin{tabular}{|c|c|c|c|c|}
\hline Characteristic & N (\%) & $\begin{array}{c}\text { All Fellows have } \\
\text { Anesthesia } \\
\text { Residency Training } \\
\text { (N, \%) }\end{array}$ & $\begin{array}{c}\text { In favor of ACGME } \\
\text { Requirement } \\
\text { for Learning USG? } \\
(\mathrm{N}, \%)\end{array}$ & $\begin{array}{l}\text { USG will eventually } \\
\text { Replace fluoroscopy } \\
(\mathbf{N}, \%)\end{array}$ \\
\hline $\begin{array}{l}\text { Setting } \\
\text { University-based } \\
\text { Other }\end{array}$ & $\begin{array}{r}34(79.1 \%) \\
9(20.9 \%)\end{array}$ & $\begin{array}{r}12(35.3 \%) \\
5(55.6 \%)\end{array}$ & $\begin{array}{r}10(71.4 \%) \\
4(28.6 \%)\end{array}$ & $\begin{array}{c}3(8.8 \%) \\
0(0 \%)\end{array}$ \\
\hline $\begin{array}{l}\text { Program Size } \\
\text { Small ( } \leq 3 \text { spots }) \\
\text { Large ( } \geq 4 \text { spots) }\end{array}$ & $\begin{array}{l}20(46.5 \%) \\
23(53.5 \%)\end{array}$ & $\begin{array}{r}12(60.0 \%) \\
5(21.7 \%)\end{array}$ & $\begin{array}{l}7(35.0 \%) \\
7(30.4 \%)\end{array}$ & $\begin{array}{l}1(5.0 \%) \\
2(8.7 \%)\end{array}$ \\
\hline $\begin{array}{l}\text { Number of US machines available } \\
1 \text { machine } \\
\geq 2 \text { machines }\end{array}$ & $\begin{array}{l}26(60.5 \%) \\
17(39.5 \%)\end{array}$ & $\begin{array}{l}8(30.8 \%) \\
9(52.9 \%)\end{array}$ & $\begin{array}{l}6(23.1 \%) \\
8(47.1 \%)\end{array}$ & $\begin{array}{c}1(3.8 \%) \\
2(11.8 \%)\end{array}$ \\
\hline
\end{tabular}




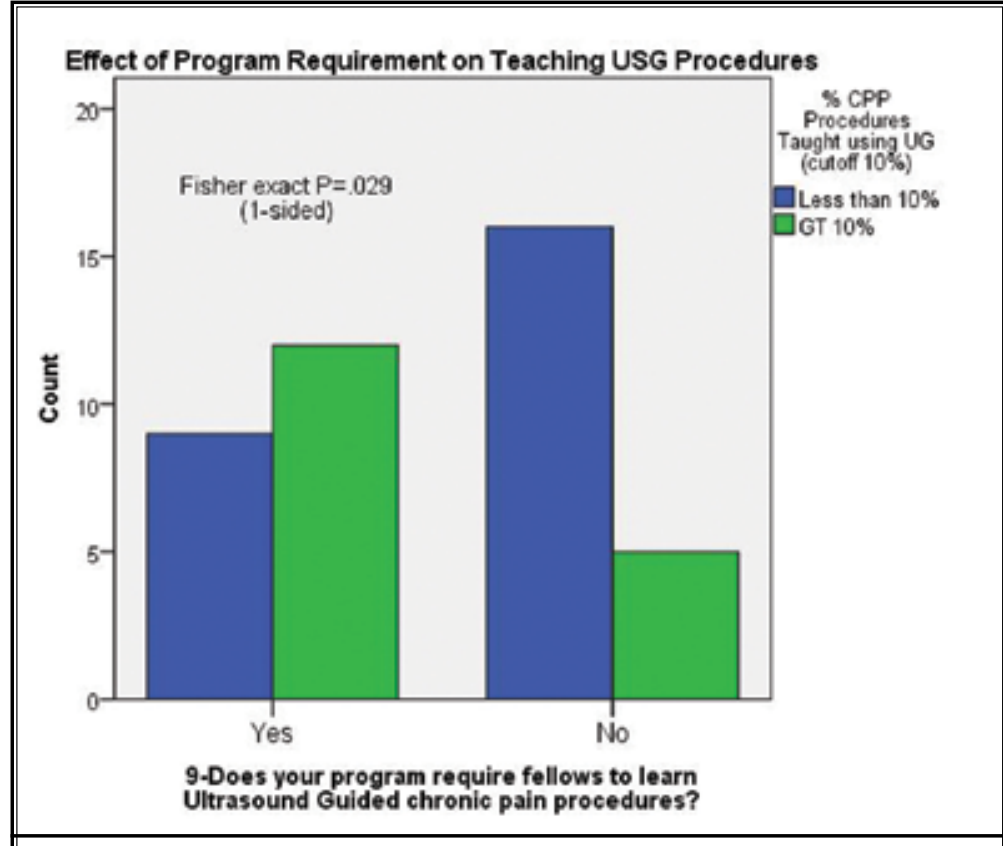

Fig. 1. Effect of program requirement on frequency of teaching ultrasoundguided procedures for chronic pain.

express interest in USG techniques for chronic pain procedures.

\section{Availability of Ultrasound Machines}

Pain fellowship programs ranged from only one machine $(60.5 \%)$ to 6 machines $(2.3 \%)$ available. The number of ultrasound machines is not correlated with program size ( $r s=-.066, N S)$ or the number of fellows who had prior anesthesia training ( $r s=-.024$ NS). Programs with only one ultrasound machine seem more likely to have fellows with mixed training backgrounds.

\section{Faculty Use of Ultrasound}

Programs were queried about the extent to which faculty members complete approximately $50 \%$ of all chronic pain procedures (CPP) using USG as the only guidance technique. The predominant answer to this question was "none" $(n=31,72.1 \%)$. Twelve programs report varying degrees of faculty utilization of USG for CPP. There are 10 programs $(23.3 \%)$ where all the faculty use USG for at least some of their CPP. However, 17 programs (39.6\%) report that over $50 \%$ of the faculty do not use USG for any of their CPP.

\section{D Technology}

This technology is presently found only at university-based programs, though it is still in the minority. Only 7 programs $(16.3 \%)$ currently report use of 3D ultrasound, but it is generally used in less than $10 \%$ of cases.
Teaching of Ultrasound Guidance for Chronic Pain Procedures

Over half of the responding programs $(58.1 \%)$ report that fellows are taught less than $10 \%$ of CPP under USG. Another 13 programs (30.2\%) report that less than one third of the procedures are taught under USG. Four programs account for the remainder, spanning from $31 \%$ to over $90 \%$ of CPP taught under USG.

\section{Program Requirements}

Nearly half $(48.8 \%)$ of all pain fellowship programs require fellows to learn USG techniques for chronic pain. Not surprisingly, use of USG is significantly more common in programs where it is a requirement (Fig. 1).

\section{ACGME Requirement}

One third $(32.6 \%)$ of program directors favor an ACGME requirement for teaching USG during pain fellowship training. In university-based programs, only $29.4 \%$ of program directors endorse such a mandatory requirement for fellowship training at this time (Fig. 2). The difference in opinion between program directors of university-based and other programs was not statistically significant. As to what the number of required procedures should be, if such a requirement were to be established, the sample split at a median of 20 procedures. An additional $31 \%$ of respondents felt that 30 procedures should be performed.

\section{Performance of Nerve Blocks for Chronic Pain using Ultrasound Guidance}

We tabulated responses for specific nerve blocks within general categories (e.g., cranial, cervical, thoracic, lumbar); the results are shown in Table 2. However in most cases, the most common response within each category of blocks was the response "none." Fig. 3 shows the percentage of blocks within each 
category performed using USG (calculated as $100 \%$ minus "none").

\section{Factors Favoring and Opposing the Teaching of Ultrasound for Chronic Pain Procedures}

\section{Factors Facilitating the Teaching of Ultrasound}

The majority of program directors $(62.8 \%)$ responded that it was necessary to train faculty in the use of the technique before it would be fully incorporated into fellowship training. This opinion was widespread among both university-affiliated programs and programs in other settings, regardless of program size or number of ultrasound machines available. Expression of interest by fellows in learning the technique was acknowledged by $32.6 \%$ of program directors, most commonly among the larger programs $(43.5 \%)$ and those with 2 or more ultrasound machines $(41.2 \%)$. Other factors cited were reimbursement issues $(16.3 \%)$ and less radiation exposure (23.3\%) compared to fluoroscopy.

\section{Factors Opposing the Teaching of Ultrasound}

The most frequently endorsed factor, given by 21 program directors $(48.8 \%)$, was that ultrasound is more time consuming than fluoroscopy. This opinion was especially frequent among programs with only one ultrasound machine $(65.4 \%)$ compared to 2 or more machines ( $23.5 \%, P=.012$ by Fisher's Exact test, two-sided). Lack of availability of ultrasound machines was the next most frequently cited factor $(27.9 \%)$. Difficulty ruling out inadvertent intravascular injection, in comparison to fluoroscopy, was cited by only 7 (16.3\%) of the respondents. Lack of evidence base for safety of USG was chosen by only 5 program directors (11.6\%), 3 of whom were at the larger university-based programs. Lack of fellows interest was cited by only 3 programs $(7.0 \%), 2$ of which were among the smaller, community-based programs.

\section{Future Utilization of Ultrasound for Chronic Pain Procedures}

Nineteen (44.2\%) program directors agreed

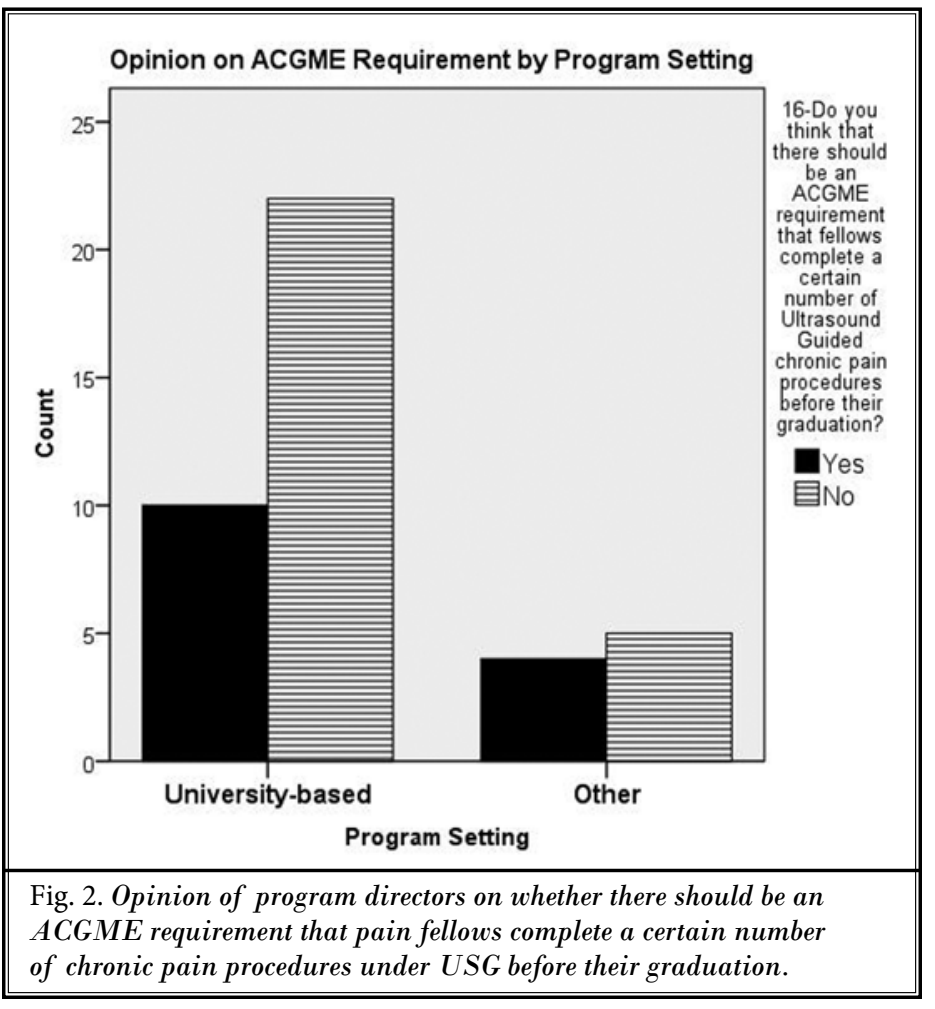

that ultrasound will never replace fluoroscopy. This feeling was somewhat more prominent among university-based $(47.1 \%)$ than among community-based programs $(33.3 \%)$ and was found about equally among programs having only one or more than one ultrasound machines. Only 3 (7.0\%) program directors were willing to state unequivocally that ultrasound would eventually replace fluoroscopy. Eleven $(25.6 \%)$ agreed that utilization of USG would remain limited until a functional 3D ultrasound machine was available. This opinion was more frequently given by directors of the larger (> 4 spots) fellowship programs (39.1\%) vs. smaller programs ( $10.0 \%, P=.039$ by Fisher's Exact test, two-sided).

\section{Discussion}

The prevalence of chronic pain in the United States is $30.7 \%$ and growing (10), yet most patients remain underserved and often do not find effective relief of their painful conditions. This is in part due to lack of training and lack of awareness of pain providers about new approaches in pain management, as well as lack of equipment and resources. Using USG instead of fluoroscopy not only decreases the risk of radiation exposure but also provides an easy way to do the procedures using a machine that is of lower cost and also can be easily transported and used in more than one location. The benefits of utilizing USG in chronic pain 
Table 2. Frequency of performance of blocks under USG in fellowship programs.

\begin{tabular}{|c|c|c|}
\hline $\begin{array}{c}\text { Class of } \\
\text { Block }\end{array}$ & Block & $\begin{array}{l}\mathrm{N}(\%) \text { of programs } \\
\text { teaching under USG }\end{array}$ \\
\hline \multicolumn{3}{|l|}{ Cranial } \\
\hline & $\begin{array}{l}\text { Greater and Lesser Occipital Nerve Blocks } \\
\text { Facial Nerve Block } \\
\text { Trigeminal Nerve Block } \\
\text { Sphenopalatine Ganglion Block } \\
\text { None }\end{array}$ & $\begin{array}{r}22(51.2 \%) \\
1(2.3 \%) \\
2(4.7 \%) \\
0(0 \%) \\
19(44.2 \%)\end{array}$ \\
\hline \multicolumn{3}{|l|}{ Cervical } \\
\hline & $\begin{array}{l}\text { Cervical Interlaminar Epidural steroid injection } \\
\text { Cervical Transforaminal Epidural steroid injection } \\
\text { Cervical Medial Branch Diagnostic blocks } \\
\text { Cervical Medial Branch Radiofrequency ablation } \\
\text { Cervical Facet Intraarticular injection } \\
\text { None }\end{array}$ & $\begin{array}{r}0(0 \%) \\
0(0 \%) \\
4(9.3 \%) \\
1(2.3 \%) \\
0(0 \%) \\
36(83.7 \%)\end{array}$ \\
\hline \multicolumn{3}{|l|}{ Thoracic } \\
\hline & $\begin{array}{l}\text { Thoracic Interlaminar Epidural steroid injection } \\
\text { Thoracic Transforaminal Epidural steroid injection } \\
\text { Thoracic Medial Branch Diagnostic blocks } \\
\text { Thoracic Medial Branch Radiofrequency ablation } \\
\text { Thoracic Facet Steroid injections } \\
\text { None }\end{array}$ & $\begin{array}{r}2(4.7 \%) \\
0(0 \%) \\
1(2.3 \%) \\
0(0 \%) \\
0(0 \%) \\
36(83.7 \%) \\
\end{array}$ \\
\hline \multicolumn{3}{|l|}{ Lumbar } \\
\hline & $\begin{array}{l}\text { Lumbar Interlaminar Epidural steroid injection } \\
\text { Lumbar Medial Branch Diagnostic blocks } \\
\text { Lumbar Medial Branch Radiofrequency ablation } \\
\text { Lumbar Facet Intraarticular Steroid injections } \\
\text { None }\end{array}$ & $\begin{array}{r}6(14.0 \%) \\
5(11.6 \%) \\
1(2.3 \%) \\
3(7.0 \%) \\
30(69.8 \%)\end{array}$ \\
\hline \multicolumn{3}{|c|}{ Autonomic } \\
\hline & $\begin{array}{l}\text { Stellate Ganglion Block } \\
\text { Splanchnic Nerve Block } \\
\text { Celiac Plexus Block } \\
\text { Hypogastric Plexus Block } \\
\text { Ganglion of Impar Block } \\
\text { Lumbar Sympathetic Block } \\
\text { None }\end{array}$ & $\begin{array}{r}23(53.5 \%) \\
1(2.3 \%) \\
0(0 \%) \\
0(0 \%) \\
1(2.3 \%) \\
0(0 \%) \\
16(37.2 \%)\end{array}$ \\
\hline \multicolumn{3}{|c|}{ Peripheral Nerve } \\
\hline & $\begin{array}{l}\text { Lateral Femoral Cutaneous Nerve Block } \\
\text { Genito Femoral Nerve Block } \\
\text { Iliohypogastric Nerve Block } \\
\text { Ilioinguinal Nerve Block } \\
\text { Peroneal Nerve Block } \\
\text { Intercostal Nerve Block } \\
\text { Pudendal Nerve Block } \\
\text { None }\end{array}$ & $\begin{array}{r}32(74.4 \%) \\
28(65.1 \%) \\
31(72.1 \%) \\
34(79.1 \%) \\
16(37.2 \%) \\
28(65.1 \%) \\
15(34.9 \%) \\
4(9.3 \%) \\
\end{array}$ \\
\hline \multicolumn{3}{|c|}{ Musculoskeletal Procedures } \\
\hline & $\begin{array}{l}\text { Trigger Points Injection } \\
\text { Sacroiliac Joint steroid injection } \\
\text { Costochondral Junction injection } \\
\text { Knee Joint injection } \\
\text { Acromioclavicular Joint injection } \\
\text { Ankle Joint injection } \\
\text { None }\end{array}$ & $\begin{array}{r}18(41.9 \%) \\
14(32.6 \%) \\
10(23.3 \%) \\
16(37.2 \%) \\
16(37.2 \%) \\
5(11.6 \%) \\
13(30.2 \%) \\
\end{array}$ \\
\hline \multicolumn{3}{|c|}{ Implantable Device } \\
\hline & $\begin{array}{l}\text { Intrathecal pump refill } \\
\text { Implantation of peripheral nerve stimulator(s) } \\
\text { Spinal cord stimulator } \\
\text { None }\end{array}$ & $\begin{array}{r}9(20.9 \%) \\
10(23.3 \%) \\
0(0 \%) \\
27(62.8 \%)\end{array}$ \\
\hline
\end{tabular}

also extend to its value in completing procedures where fluoroscopic guidance will not be as helpful. Examples include the application of USG for neural cryoablation (11) and in many other cases which could not be as accurately and safely performed without USG $(12,13,14)$. Ultrasound is also utilized for guided joint and tendon injections (15). Intravascular injection is not only detected using USG as in the case of fluoroscopy, but can also be prevented $(16,17)$. Thus using the USG technique for completing some chronic pain procedures increases safety compared to fluoroscopy alone. Perhaps the 2 methods may need to be used hand in hand while doing procedures in which inadvertent intravascular injections could be detrimental.

The response rate for our survey is slightly lower (46.7\%) than in a similar survey $(62 \%)$ of USG for regional anesthesia in anesthesia residency programs (3). Given that we surveyed the entire population ( $n=92$ ) of pain fellowship programs in the United States as of 2012, we believe that our response rate of $46.7 \%$ is reasonable and that our results give a fair representation of the current use of USG for CPP, at least in university-based programs. We recognize that a higher response rate would be more desirable. The fact that we surveyed the program directors themselves results in more accurate data collection and that should compensate for the somewhat low response rate.

We were able to collect data that provided us with information about the different procedures in chronic pain where ultrasound is widely used in current practice. Specifically, these include stellate ganglion block, occipital nerve blocks, and most peripheral nerve 
blocks. With these procedures currently being done under USG, we think there should be an ACGME guideline on the teaching of this technique, at least for these procedures.

In this survey study, we have obtained better information and understanding about the current state of fellowship education in chronic pain management using USG. Facilitating factors as well as barriers to the use of ultrasound for these procedures have been identified. Factors favoring the teaching of ultrasound include high levels of interest among pain fellows and reduced level of radiation exposure, as well as reimbursement considerations. These factors differ from those identified in a prior survey of USG in residency training. In the latter, improved safety and success rate of the procedures were paramount factors, along with the desire to teach the technique to residents (3). The barriers cited by our survey respondents primarily include lack of faculty training and lack of access to equipment. These barriers are the same ones identified in a prior survey of the use of USG for peripheral nerve blocks in anesthesia residency training (3). Addressing these factors will facilitate the teaching and eventually the utilization of this costeffective modality for completing chronic pain interventions.

Recently Bhatia and Brull (2013) (18) performed a meta-analysis of 41 case series and 5 randomized trials and concluded that although as yet there is insufficient data to support the efficacy of the technique, USG for CPP can match or improve performance and safety-related outcomes compared with other techniques based on anatomic landmarks, nerve stimulation, and fluoroscopy. The meta-analysis study found increased safety with USG in performing injections for cervical nerve root, cervical sympathetic trunk, suprascapular nerve, and pudendal nerve as compared to traditional techniques. The meta-analysis also demonstrated that the efficacy of performing blocks on lumbar facet joint nerve, lumbar nerve root, greater occipital nerve, suprascapular intercostal nerve, and lateral femoral cutaneous nerve, as well as lumbar facet intraarticular injec-

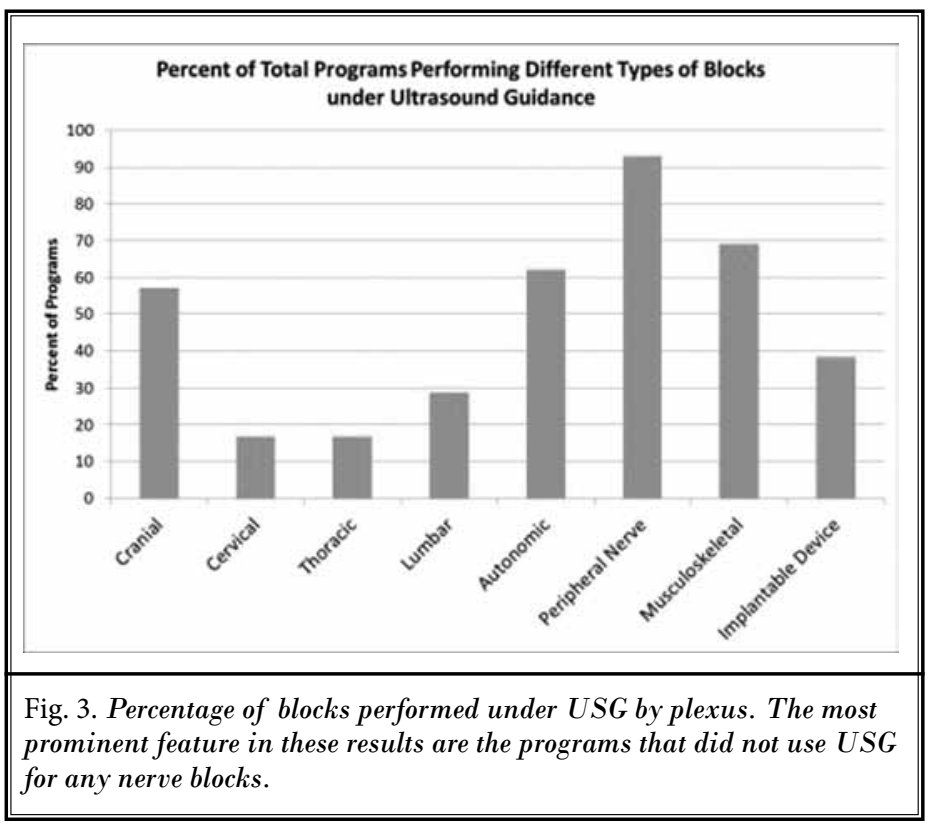

tions, is comparable to the efficacy of traditional techniques of completing these blocks at this time.

Our data show that the teaching of ultrasound guided CPP varies significantly between individual pain medicine fellowship programs. One explanation for this variation relates to the low number of ultrasound machines available for training, even in many of the larger fellowship programs. The data we report also show that there is a discrepancy between the high level of interest among pain fellows in learning CPP techniques under USG, and the low level at which fellowship faculty utilize and teach the technique. Our study showed that in more than $60 \%$ of programs, over $90 \%$ of fellows have expressed interest in learning the technique. This level of interest should lead to implementing a structured training on this technique in pain fellowship programs.

In an international collaborative effort, the joint committee of the American, European, and the Asian Australasian Societies of Regional Anesthesia and Pain identified 3 levels of difficulty for the different pain blocks (19). We found that these identified levels of difficulty to a great extent are concordant with the input of the program directors we surveyed in terms of the frequency of performing such chronic pain blocks.

The known limitations of utilizing the technique and the fact that the ability to perform it is operator dependent, may explain the wide variation in the frequency of utilizing the technique. Though many program directors require that fellows demonstrate competency in the technique before graduation, as of today there is no ACGME guideline requiring this (5). The mastery of the technique for at least for level 1 difficulty procedures (19) is no longer an option, but is in fact an essential part 
of the competent management of chronic pain.

We believe that using cadavers is the most convenient way for teaching and learning the USG technique. This method has proved helpful in the teaching of acute pain blocks $(20,21,22)$ and will likely also be helpful in learning and gaining confidence for using ultrasound in CPP. Also, using video analysis of learning the technique as was done in the teaching of acute pain blocks could be similarly helpful (23).

\section{Conclusion}

In conclusion, our survey data show that the teaching of USG for CPP varies significantly between individual programs. Nearly half of US-based pain medicine fellowship programs currently require that fellows demonstrate competency in the technique before graduation. The joint committees of the American, European, Asian, and Australasian pain societies recommend training guidelines that provide a structure for attaining and maintaining the proper levels of competency, proficiency, and quality improvement. Yet there are at present no ACGME guidelines regarding teaching the technique. We agree that the advancement to 3D technology and an increase in the number of trained faculty will significantly impact the utilization and teaching of this technique. In the meantime we recommend that there should be ACGME guidelines that mandate that pain medicine fellows should learn a certain number of the blocks which are categorized as level one difficulty. This will be a significant factor in attracting attention about the importance of USG and will increase the familiarity of the technique among pain providers. This will ultimately result in better chronic pain management which can be made available to patients living in remote areas with fewer medical resources.

\section{Acknowledgment}

We thank Ashima Muttreja B.S., and Sabeen Rizwan B.A. for their assistance in conducting this study. We extend our deepest appreciation to David Cyrille M.S. for his assistance with computer support and the RedCap system. Also we are grateful for the advice received from Wei-Hsin Lu Ph.D., Office of the Dean of Medicine, and from Elinor Schoenfeld Ph.D. and Elza Mylona Ph.D. of the Dept. of Preventive Medicine, Stony Brook University School of Medicine.

\section{Author Contributions}

Dr. Asaad and Dr. Durkin designed the study protocol. Dr. Asaad designed the survey and implemented the questions on REDCap software. He managed the literature searches and summaries of previous related work and wrote the first draft of the manuscript. Dr. Durkin, Dr. Reinsel, Dr. Moten, and Dr. DeVeaux assisted in recruitment and follow-up of survey respondents. Dr. Reinsel had full access to all the data in the study and takes responsibility for the integrity of the data and the accuracy of the data analysis. Dr. Reinsel wrote the Methods and Results sections and assembled the final version of the manuscript for publication.

\section{References}

1. Sites BD, Chan VW, Neal JM, Weller R, Grau T, Koscielniak-Nielsen ZJ, Ivani G. The American Society of Regional Anesthesia and Pain Medicine and the European Society of Regional Anaesthesia and Pain Therapy Joint Committee recommendations for education and training in ultrasound-guided regional anesthesia. Reg Anesth Pain Med 2009; 34:40-46.

2. Neal JM, Brull R, Chan VWS, Grant SA, Horn J-L et al. The ASRA evidence-based medicine assessment of ultrasoundguided regional anesthesia and pain medicine. Reg Anesth Pain Med 2010; 35, Suppl. 1,S1-S9.

3. Helwani MA, Saied NN, Asaad B, Rasmussen $\mathrm{S}$, Fingerman ME. The current role of ultrasound use in teaching regional anesthesia: A survey of residency programs in the United States. Pain Med 2012; 13:1342-1346.

4. $\quad$ Peng PW, Narouze S. Ultrasound-guided interventional procedures in pain medicine: A review of anatomy, sonoanatomy, and procedures: part I: nonaxial structures. Reg Anesth Pain Med 2009; 34:458-474.

5. Narouze SN. Ultrasound-guided interventional procedures in pain management: Evidence-based medicine. Reg Anesth Pain Med 2010; 35:S55-58.

6. Narouze S, Peng PW. Ultrasound-guided interventional procedures in pain medicine: A review of anatomy, sonoanatomy, and procedures. Part II: Axial structures. Reg Anesth Pain Med 2010; 35:386-396.

7. Jones D, Story D, Clavisi O, Jones R, Peyton $\mathrm{P}$. An introductory guide to survey research in anaesthesia. Anaesth Intensive Care 2006; 34: 245-253.

8. Harris PA, Taylor R, Thielke R, Payne J, Gonzalez N, Conde JG. Research electronic data capture (REDCap) - A metadata-driven methodology and workflow process for providing translational research informatics support. J Biomed Inform 2009; 42:377-381.

9. Benzon HT, Huntoon MA, Zell C, Stock MC. The present status of fellowships in pain medicine. American Society of Anesthesiologists Newsletter 2008; 72:8-12.

10. Johannes CB, Le TK, Zhou X, Johnston $J A$, Dworkin $\mathrm{RH}$. The prevalence of chronic pain in United States adults: Results of an Internet-based survey. Journal of Pain 2010; 11:1230-1239.

11. Connelly NR, Malik A, Madabushi L, 
Gibson C. Use of ultrasound-guided cryotherapy for the management of chronic pain states. J Clin Anesth 2013; 25:634-636.

12. Thomas K, Shankar H. Targeting myofascial taut bands by ultrasound. Curr Pain Headache Rep 2013 17:349.

13. Hong MJ, Kim YD, Seo DH. Successful treatment of abdominal cutaneous entrapment syndrome using ultrasound guided injection. Korean J Pain 2013; 26:291-294.

14. Mautner K, Colberg RE, Malanga G, Borg-Stein JP, Harmon KG, Dharamsi AS, Chu S, Homer P. Outcomes after ultrasound-guided platelet-rich plasma injections for chronic tendinopathy: A multicenter, retrospective review. PM $R$ 2013; 5:169-175.

15. Ferrero G, Fabbro E, Orlandi D, Martini C, Lacelli F, Serafini G, Silvestri E, Sconfienza LM. Ultrasound-guided injection of platelet-rich plasma in chronic Achilles and patellar tendinopathy. J Ultrasound 2012; 15:260-266.
16. Narouze, SN. Ultrasound-Guided Cervical Spine Injections: Ultrasound "prevents" whereas contrast fluoroscopy "detects" intravascular injections. Reg Anesth Pain Med 2012; 37:127-130.

17. Narouze S. Beware of the "serpentine" inferior thyroid artery while performing stellate ganglion block. Anesth Analg 2009; 109:289-290.

18. Bhatia A, Brull R. Review article: is ultrasound guidance advantageous for interventional pain management? A systematic review of chronic pain outcomes. Anesth Analg 2013; 117:236-251.

19. Narouze SN, Provenzano D, Peng P, Eichenberger U, Lee SC, Nicholls B, Moriggl B; American Society of Regional Anesthesia and Pain Medicine; European Society of Regional Anaesthesia and Pain Therapy; Asian Australasian Federation of Pain Societies. The American Society of Regional Anesthesia and Pain Medicine, the European Society of Regional Anaesthesia and Pain Therapy, and the Asian Australasian Federation of
Pain Societies Joint Committee recommendations for education and training in ultrasound-guided interventional pain procedures. Reg Anesth Pain Med. 2012; 37:657-664.

20. Tsui BC, Dillane D, Pillay J, Ramji AK, Walji AH. Cadaveric ultrasound imaging for training in ultrasound-guided peripheral nerve blocks: Lower extremity. Can J Anaesth 2007; 54:475-480.

21. Tsui BC, Dillane D, Walji AH. Cadaveric ultrasound imaging for training in ultrasound-guided peripheral nerve blocks: Upper extremity. Can J Anaesth 2007; 54: 392-396.

22. Kessler J, Moriggl B, Grau T. Ultrasoundguided regional anesthesia: Learning with an optimized cadaver model. Surg Radiol Anat 2014; 36:383-392.

23. Sites BD, Spence BC, Gallagher JD, Wiley CW, Bertrand ML, Blike GT. Characterizing novice behavior associated with learning ultrasound-guided periphera regional anesthesia. Reg Anesth Pain Med 2007; 32:107-115. 
